Article

\title{
Eco-Friendly Reduced Graphene Oxide Nanofilter Preparation and Application for Iron Removal
}

\author{
Pankaj Kumar Jha ${ }^{1}$, Watsa Khongnakorn ${ }^{2,+}$ (D) , Chamorn Chawenjkigwanich ${ }^{3,+}{ }^{+}$Md Shahariar Chowdhury ${ }^{1,4}$ \\ and Kuaanan Techato $1,4, *$ (D) \\ 1 Faculty of Environmental Management, Prince of Songkla University, Hat Yai, Songkhla 90110, Thailand; \\ nanoscience.jha.pankaj@gmail.com (P.K.J.); mdshahariar.c@psu.ac.th (M.S.C.) \\ 2 Centre of Excellent in Membrane Science and Technology, Prince of Songkla University, Hat Yai, \\ Songkhla 90110, Thailand; watsa.k@psu.ac.th \\ 3 Environmental Nanotechnology Team, National Nanotechnology Center, National Science and Technology \\ Development Agency, Thailand Science Park, Paholyothin Road, Pathum Thani 12120, Thailand; \\ chamorn@nanotec.or.th \\ 4 Environmental Assessment and Technology for Hazardous Waste Management Research Center, Faculty of \\ Environmental Management, Prince of Songkla University, Hat Yai, Songkhla 90110, Thailand \\ * Correspondence: kuaanan.t@psu.ac.th \\ + Second Author.
}

check for updates

Citation: Jha, P.K.; Khongnakorn, W.; Chawenjkigwanich, C.; Chowdhury, M.S.; Techato, K. Eco-Friendly Reduced Graphene Oxide Nanofilter Preparation and Application for Iron Removal. Separations 2021, 8, 68. https://doi.org/10.3390/ separations 8050068

Academic Editors: Federica Bianchi and Ernesto Reverchon

Received: 4 March 2021

Accepted: 14 May 2021

Published: 19 May 2021

Publisher's Note: MDPI stays neutral with regard to jurisdictional claims in published maps and institutional affiliations.

Copyright: (C) 2021 by the authors. Licensee MDPI, Basel, Switzerland. This article is an open access article distributed under the terms and conditions of the Creative Commons Attribution (CC BY) license (https:/ / creativecommons.org/licenses/by/ $4.0 /)$.
Abstract: In this paper, the green synthesis of reduced graphene oxide (r-GO) nanomaterials using Callistemon viminalis leaf extract as a reducing and stabilizing agent is reported for the first time. The synthesized r-GO nanomaterials were characterized using UV-Vis, XRD, FE-SEM, TEM, and energy dispersive $\mathrm{X}$-ray (EDX) analyses. The nanofilter membrane was prepared by varying the amounts of r-GO nanomaterials in a Polysulfone-N,N-dimethyl formamide (DMF) solution. The nanofilter membrane was characterized by the contact angle, atomic force microscopy (AFM), UVVis, and FTIR. The results confirm the formation of r-GO nanomaterials. Higher amounts of r-GO nanomaterials in the membrane show a lower contact angle, thus confirming their hydrophilic nature. Iron water filtration was performed with different amounts of r-GO nanomaterials in the membrane filter, and the water flux was smooth over an increased time period. Inductively Coupled Plasma (ICP) analysis showed a higher percentage of iron rejection (95.77\%) when higher amounts (0.10 g) of r-GO nanomaterials were used in a mixed membrane (i.e., sample C). In conclusion, the findings illustrate that Callistemon viminalis mediates the synthesis of $\mathrm{r}-\mathrm{GO}$ nanomaterials, which is useful in water filtration, and can be incorporated into membrane filters, since it removes iron.

Keywords: biosynthesis method; reduced graphene oxide (r-GO) nanomaterials; nano-filtration; iron contaminants removal; cost-effective

\section{Introduction}

Pure drinking water is essential for human health. Health can be negatively affected by the contaminants present in drinking water [1]. Heavy metals have a higher density than water, and various heavy metals that are present in the earth's crust mix with water and affect human health after consumption. Toxic heavy metals' effects on genetic materials alter normal body metabolism [2]. Heavy metals, such as chromium, lead, manganese, mercury, zinc, cadmium, and iron, have more toxic effects on human health [3]. An overdose of iron causes hemochromatosis. The World Health Organization (WHO) reported the growth of iron bacteria and $0.3 \mathrm{mg} / \mathrm{L}$ as an unnoticeable amount of iron concentration present in underground well-water that causes health issues, mostly in developing countries [4]. Contaminants from industrial waste and wastewater from households connected to rivers pose a major challenge in water management. The standard filtration method of ionic removal of toxic heavy metal from is inefficient [5], but small pore sizes in membrane filtration were shown to be effective in water filtration [6]. 
A literature review shows that graphene is a single-layered sheath derived from graphite. Graphene oxide (GO), containing an oxygen group, is hydrophilic [7]; during heavy metal removal from water, graphene filters bind with metal ions, thus blocking large molecules and solving drinking water problems [8]. Conventionally, reduced graphene oxide ( $\mathrm{r}-\mathrm{GO}$ ) nanomaterials are produced using physical and chemical methods, which costly for mass production and hazardous to the environment. In the present situation, an eco-friendly and cost-effective method is needed to manage environmental pollution and reduce the cost of the mass production of reduced graphene oxide nanomaterials for use in water filtration. Therefore, in this study, reduced graphene oxide was biologically synthesized from Callistemon viminalis plant leaf extract and used as a membrane filter for the removal of iron metal ions from water.

The reduced graphene oxide nanomaterial was synthesized following a biological method. Reduced graphene oxide nanomaterial surface morphology was analysed using FE-SEM, chemical composition using FTIR, and particle size using XRD. The efficiency of the reduced graphene oxide membrane was measured for water permeability and heavy metal removal. The reduced graphene oxide nanomaterial, with high amounts of membrane filters, was found to be more efficient. The r-GO membrane might be used for heavy metal removal with a low-pressure driving force and a more hydrophilicity membrane to obtain better water flux.

\section{Materials and Methods}

\subsection{Materials}

We purchased a $4 \mathrm{~g}$ /L graphene oxide solution from Graphenea, San Sebastián, Spain. Iron nitrate $\mathrm{Fe}\left(\mathrm{NO}_{3}\right)_{3}$ and $\mathrm{N}$, N-dimethylformamide were supplied by Ajax Finechem Pty Ltd., Auckland, New Zealand. Sodium hydroxide pallet was purchased from Loba Chemie Pvt. Ltd., Mumbai and polysulfone pallets (UDEL P-1700) were supplied by Solvay, Beijing, China.

\subsection{Biosynthesis of Reduced Graphene Oxide Nanomaterials}

We mixed $30 \mathrm{~g}$ of Callistemon viminalis leaf with $250 \mathrm{~mL}$ of de-ionized water and boiled the mixture at $70{ }^{\circ} \mathrm{C}$ for $20 \mathrm{~min}$. After boiling, the leaf extract was filtered using Whatman filter paper no. 1 and cooled.

We mixed $10 \mathrm{~mL}$ of graphene oxide (GO) concentration solution with $100 \mathrm{~mL}$ of Callistemon viminalis leaf extract, and $25 \mathrm{~mL}$ of $0.1 \mathrm{~N}$ sodium hydroxide $(\mathrm{NaOH})$ was added. The solution was stirred at $60{ }^{\circ} \mathrm{C}$ for $2 \mathrm{~h}$ until a dark-brown color formed (Figure 1). Next, it was centrifuged at 14,000 rpm for $15 \mathrm{~min}$, and the paste was collected and dried [9].

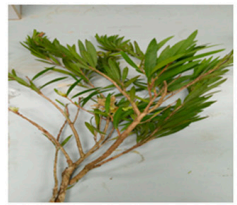

a.

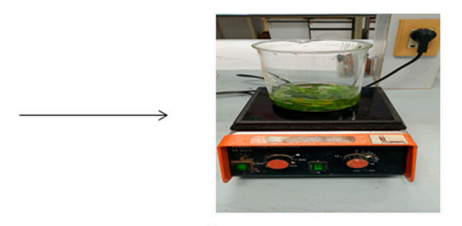

b.

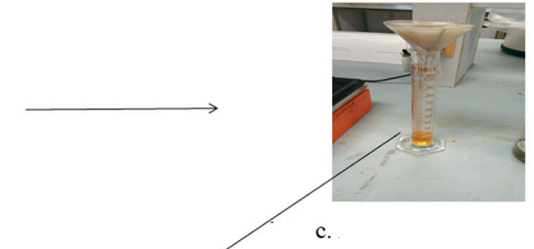

c.

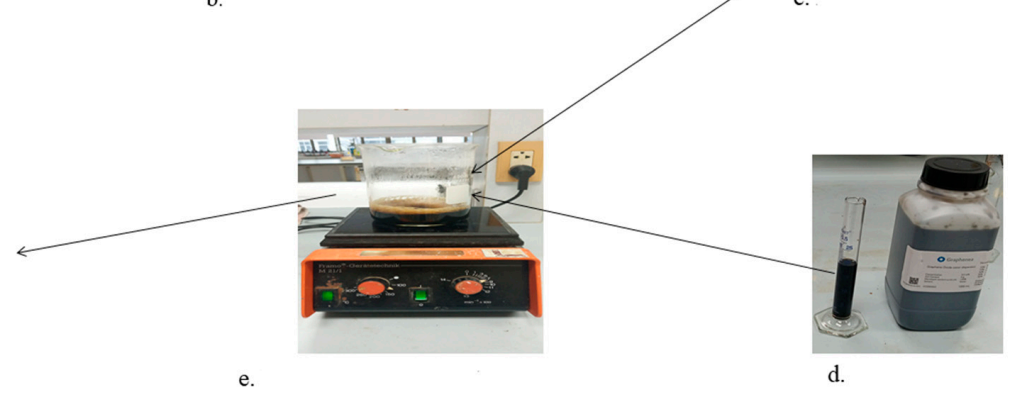

Figure 1. Reduced graphene oxide (r-GO) preparation: (a) plant leaf, (b) leaf extraction distilled water, (c) Leaf extract filtration, (d) graphene oxide (GO), (e) mixture of leaf extract and graphene oxide after vigorous stirring and (f) reduced graphene oxide. 


\subsection{Preparation of Membrane Filter}

Different types of nano-membrane were prepared by adding $0.0150 \mathrm{~g}$ (i.e., sample B) or $0.10 \mathrm{~g}$ (i.e., sample C) of r-GO powder mixed with $15 \mathrm{~g}$ of polysulfone (PSF) and $85 \mathrm{~mL}$ of $\mathrm{N}, \mathrm{N}$-dimethyl formamide (DMF) in separate bottles. One normal membrane (i.e., sample A) was prepared without adding r-GO powder in polysulfone (PSF) and N,N-dimethyl formamide (DMF). Vigorous stirring for $24 \mathrm{~h}$ and casting were performed to create a membrane layer (Figure 2) [10].

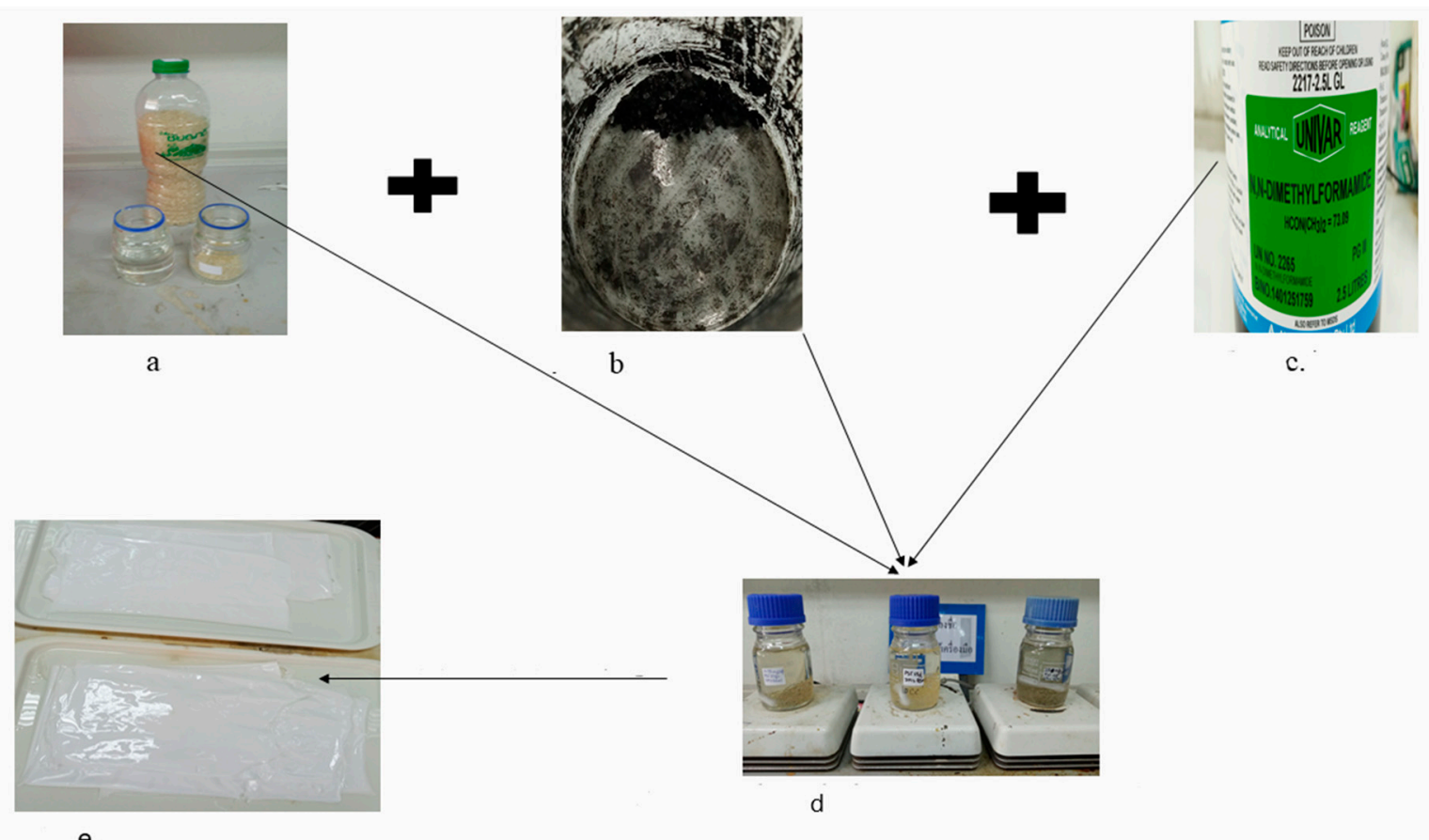

Figure 2. Membrane preparation (a) Polysulfone (b) r-GO Powder (c) N,N-dimethyl formamide (DMF) (d) Stirring the solution over night at room temperature and (e) Different membranes.

\subsection{Characterizations}

UV-Vis analysis was carried out between the wavelengths of 200 and $800 \mathrm{~nm}$ using UV-Vis spectroscopy (model number DR 6000, Envi Science company limited). The surface morphology and elemental compositions were examined using FE-SEM (Apreoenergy dispersive X-ray (EDX)). TEM analysis was carried out using an electron probe X-ray microanalyzer (JXA 8900R). The functional groups attached on the surface of the nanoparticles were analyzed by Attenuated Total Reflection (ATR) and $\mathrm{KBr}$ pallet technique using a Fourier transform infrared spectrometer (VERTEX 70, Bruker, Bremen, Germany). Surface roughness was analyzed by atomic force microscopy (AFM-flex). XRD Empyrean was used to identify peaks intensity (counts). GC-MS analysis was carried using instrument of Agilent Technologies, USA. Automatic Liquid Sampler (ALS) taking injection volume $1 \mu \mathrm{L}$. The chromatographic column was an Agilent CP9205 $(30 \mathrm{~m} \times 250 \mu \mathrm{m} \times 0.25 \mu \mathrm{m})$, with high-purity helium as the gas carrier, at a flow rate of $1 \mathrm{~mL}$ per minute and average velocity $36.796 \mathrm{~cm} / \mathrm{s}$. The injector temperature range $20^{\circ} \mathrm{C}$ to $250{ }^{\circ} \mathrm{C}$ and it was with a splitless injector. The temperature was set initially to $70^{\circ} \mathrm{C}$ hold for $5 \mathrm{~min}$ and rate was $10^{\circ} \mathrm{C}$ per minute. The MS ion source temperature was $230^{\circ} \mathrm{C}$ and maximum $250^{\circ} \mathrm{C}$ with electron energy $70 \mathrm{eV}$. The scan range was $35-650 \mathrm{amu}$, threshold 150 and the solvent delay time was $4.5 \mathrm{~min}$.

Contact angle analysis was carried out using optical contact analyzer data physics, Germany. Test condition was at temperature $23 \pm 2{ }^{\circ} \mathrm{C}$ and standards method WI-RES-contact angle-001 performed using 7 micro liter of deionized water as test liquid. Inductively cou- 
pled plasma atomic emission spectroscopy (ICP-OES) (Perkin Elmer Instruments, Shelton, CT, USA) was used for iron detection. The wavelength was $238 \mathrm{~nm}$ to $239.562 \mathrm{~nm}$ for iron determination. Parameter was axial view mode, RF power 1300 (W), nebulizer gas flow rate $0.8 \mathrm{~L}$ per minute, auxiliary gas flow rate $0.2 \mathrm{~L}$ per minute, plasma gas flow rate $15 \mathrm{~L}$ minute and sample flow rate $1.5 \mathrm{~mL}$ per minute.

\section{Results}

\subsection{GC-MS Analysis}

GC-MS analysis showed the presence of higher amounts of 2,3-butanediol, 2-butanone, 3-hydroxy- and acetic acid, catechol, 3-cyclohexene-1-methanol, and alpha, alpha,4-trimethyl (Figure 3, Table 1) [11].

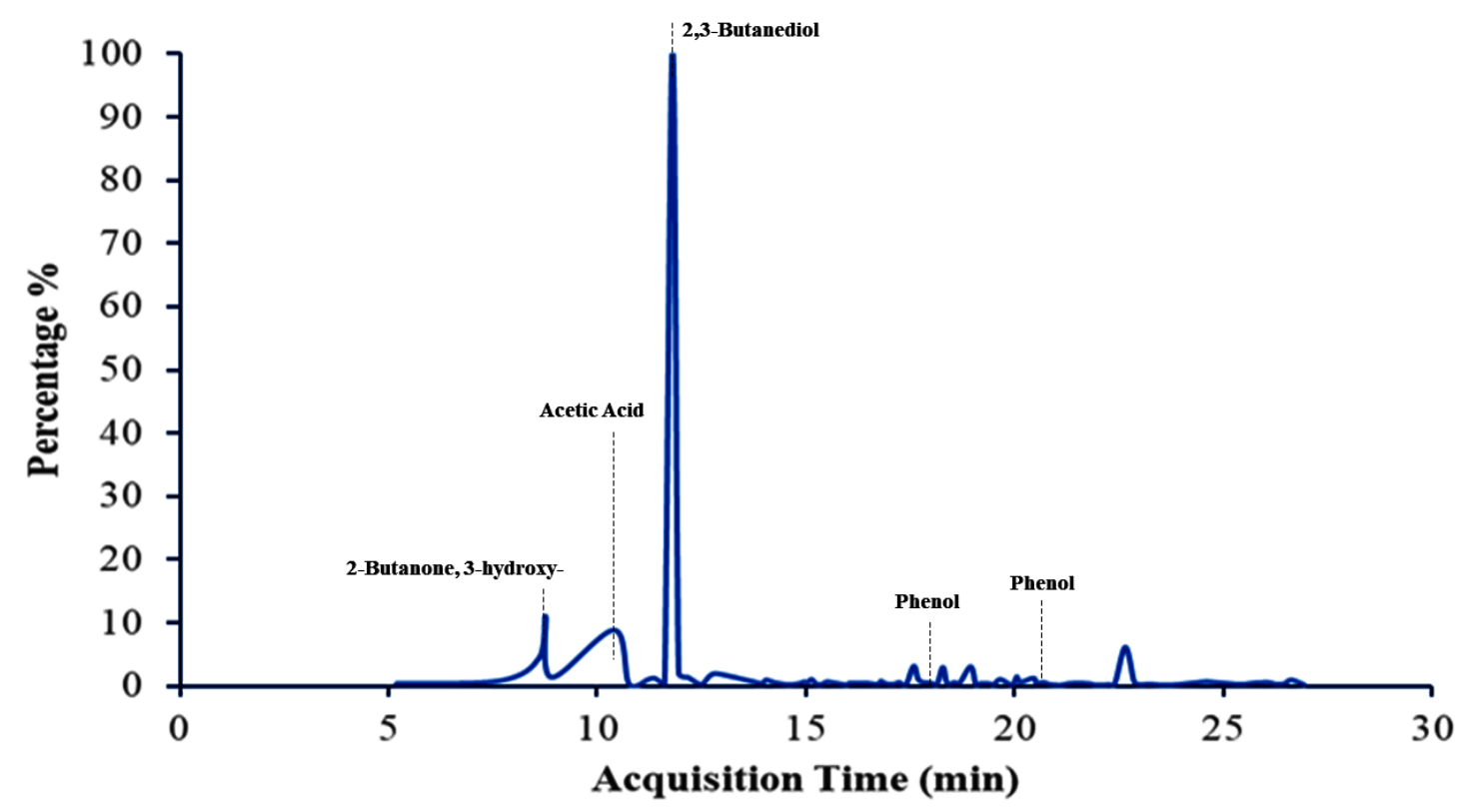

Figure 3. GC/MS analysis of Callistemon viminalis.

Table 1. Peak percentage having more than $90 \%$ match with chemical compounds.

\begin{tabular}{ccc}
\hline Acquisition Time (min) & Peak Percentage (\%) & Compound \\
\hline 8.76 & 11 & 2-Butanone, 3-hydroxy- \\
10.40 & 8.8 & Acetic acid \\
10.76 & 0.2 & 1,6-Octadien-3-ol, 3,7-dimethyl- \\
11.36 & 1.2 & 2,3-Butanediol \\
11.81 & 100 & 2,3-Butanediol \\
12.86 & 1.9 & 3-Cyclohexene-1-methanol, \\
& & alpha,alpha,4-trimethyl- \\
14.18 & 0.6 & 1,3-Cyclohexadiene, \\
& & 2-methyl-5-(1-methylethyl-, \\
14.71 & 0.2 & monoepoxide \\
15.51 & 0.6 & Benzenemethanol, \\
16.75 & 0.2 & alpha,alpha,4-trimethyl- \\
17.99 & 0.4 & Phenylethyl alcohol \\
20.46 & 1.2 & Furaneol \\
21.27 & 0.3 & Phenol, 2-methoxy-3-(2-propenyl)- \\
22.66 & 6.1 & Benzoic acid \\
24.40 & 0.5 & Phenol, 2,6-dimethoxy-4-(2-propenyl)- \\
& & Catechol \\
& & Benzenemethanol, 3,4,5-trimethoxy- \\
\hline
\end{tabular}




\subsection{UV-Vis Spectroscopy Analysis}

The UV-Vis absorbance of graphene oxide and reduced graphene oxide nanomaterials occurred at 230 and $281 \mathrm{~nm}$, respectively (Figure 4), thus confirming the formation of reduced graphene oxide nanomaterial [12].
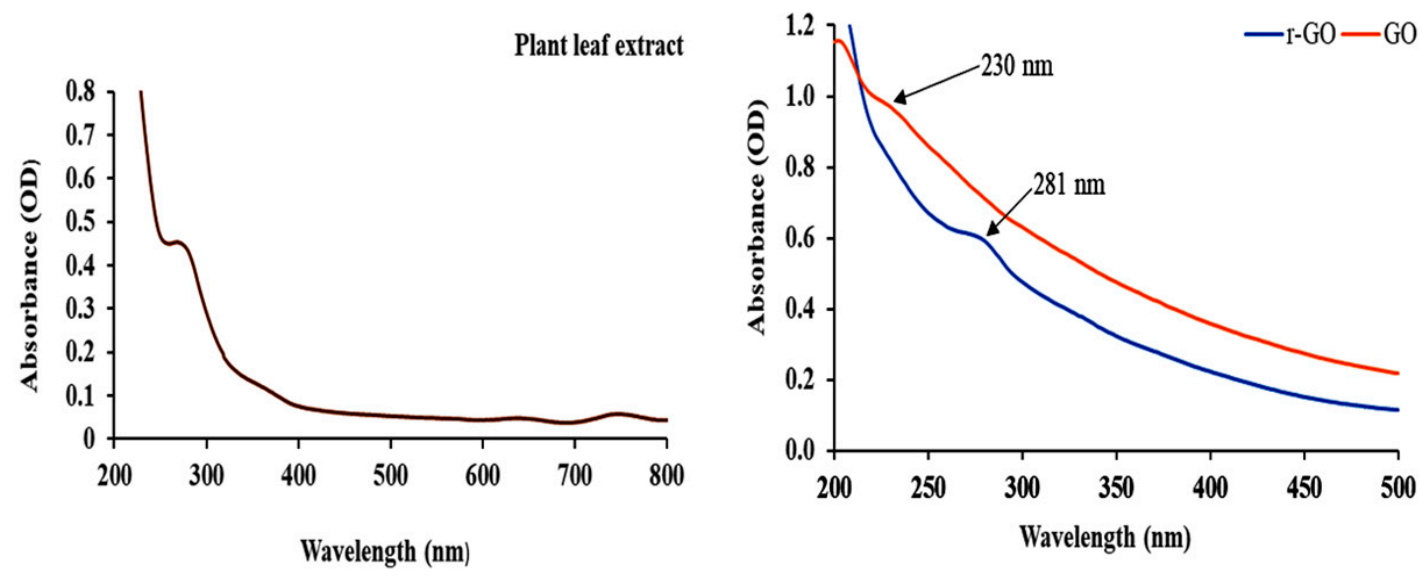

Figure 4. UV-Vis absorbance peak optical density (OD) vs. wavelength (nm).

\subsection{X-ray Diffraction (XRD) Analysis}

XRD analysis was performed using CuK $\alpha$ radiation with a wavelength $(\lambda)$ of $1.5406 \AA$ and scans in the $2 \theta$ range of $10^{\circ}$ to $80^{\circ}$. The XRD peak arms ranged from $15.6^{\circ}$ to $30.1^{\circ}$, confirming r-GO nanomaterial formation at a peak $2 \theta$ of $22^{\circ}$ with a Muller index value $(\mathrm{h}, \mathrm{k}, \mathrm{l})$ of 002 and lattice spacing of $0.4072 \mathrm{~nm}$. (Figure 5). An increase in lattice spacing showed the deoxygenation and separation of each graphene oxide sheet formed [13]. Commercial graphene oxide has an XRD peak at a $2 \theta$ of $11.613^{\circ}$.

r-G0 Nanomaterials

CommercialGo
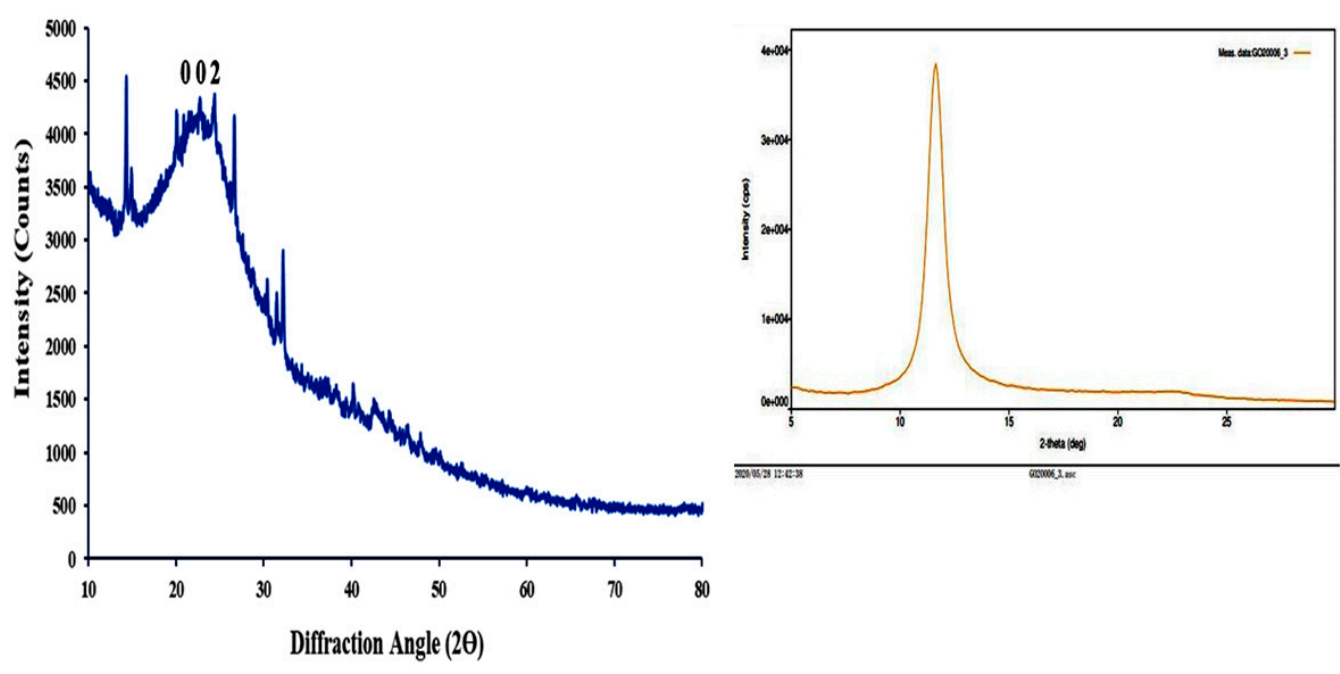

Figure 5. XRD analysis of reduced graphene oxide nanomaterial.

\subsection{Contact Angle (CA) Analysis}

An optical contact angle analyzer (Data Physics, Germany) was used to analyze the contact angle for different membranes. The average contact angles for samples A, B, and $\mathrm{C}$ were $79.4^{\circ}, 79.6^{\circ}$, and $74.2^{\circ}$, respectively, thus confirming the hydrophilic nature of the membrane. The $0.1 \mathrm{~g}$ (i.e., sample $\mathrm{C}$ ) reduced graphene oxide nanomaterial mixed membrane had the lowest contact angle and showed a more hydrophilic nature (Figure 6) [14]. 


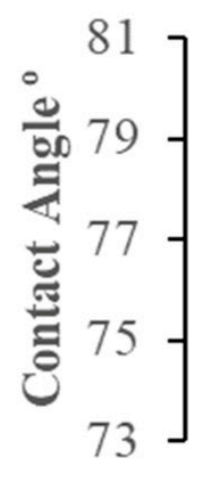

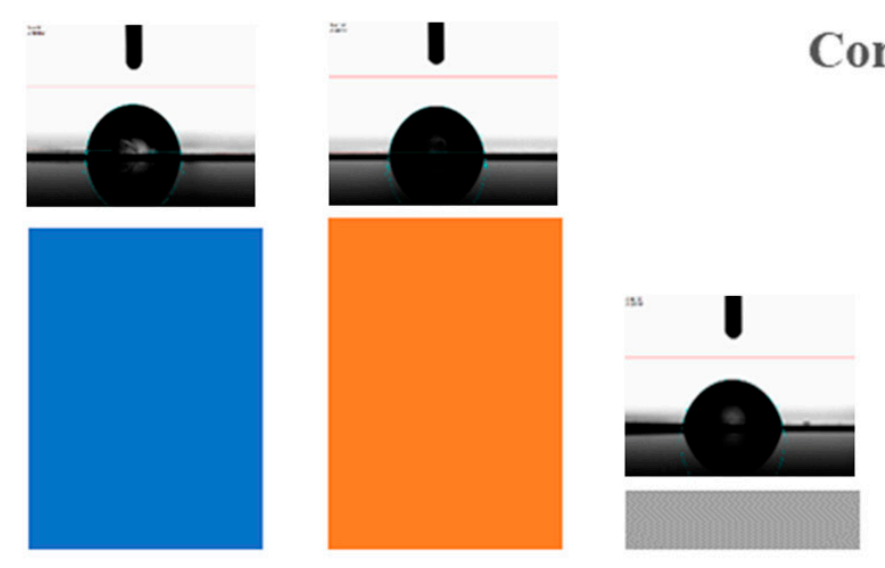

Different Type of Membranes

- PSF-DMF (Normal membrane)

0.015 gram rGO-PSF-DMF membrane

@ 0.10 gram rGO-PSF-DMF membrane

Figure 6. Contact angle for sample A, sample B, and sample C.

\subsection{Atomic Force Microscopy (AFM) Analysis}

The front and back side roughness of different membranes was analyzed at $1.2 \mu \mathrm{m}$ using nanosurface software and according to the formula,

$$
\mathrm{R}_{\mathrm{RMS}}=\sqrt{1} / n \sum_{i=1}^{n}\left|\mathrm{Z}^{2} i\right|
$$

where ' $n$ ' is integral number, ' $Z i$ ' is deviation from mean line of the roughness and RMS is Root Mean Square.

Back side roughness was also analyzed to determine the potential of the membrane for future application in reverse osmosis. The root mean square roughness of sample A was 5.9053 and $15.885 \mathrm{~nm}$ for the front and back sides of the membrane, respectively; root mean square roughness of sample B was 21.422 and $12.183 \mathrm{~nm}$ for the front and back sides, respectively. The root mean square roughness of sample $C$ was 19.991 and $9.1771 \mathrm{~nm}$ for the front and back sides, respectively (Figure 7a,b) [15].

\subsection{Field Emission Scanning Electron Microscopy (FE-SEM) Analysis}

The FE-SEM image analysis before water filtration of reduced graphene oxide nanomaterials (Figure 8a) showed a separated layer of sheets. Before iron water filtration, FE-SEM analysis for different membranes was performed. The surfaces of sample A membrane showed numerous pores with an average size of $26.57 \mathrm{~nm}$. Figure $8 \mathrm{~b}$ shows a cross-section view with an average membrane thickness of $95.21 \mu \mathrm{m}$. 


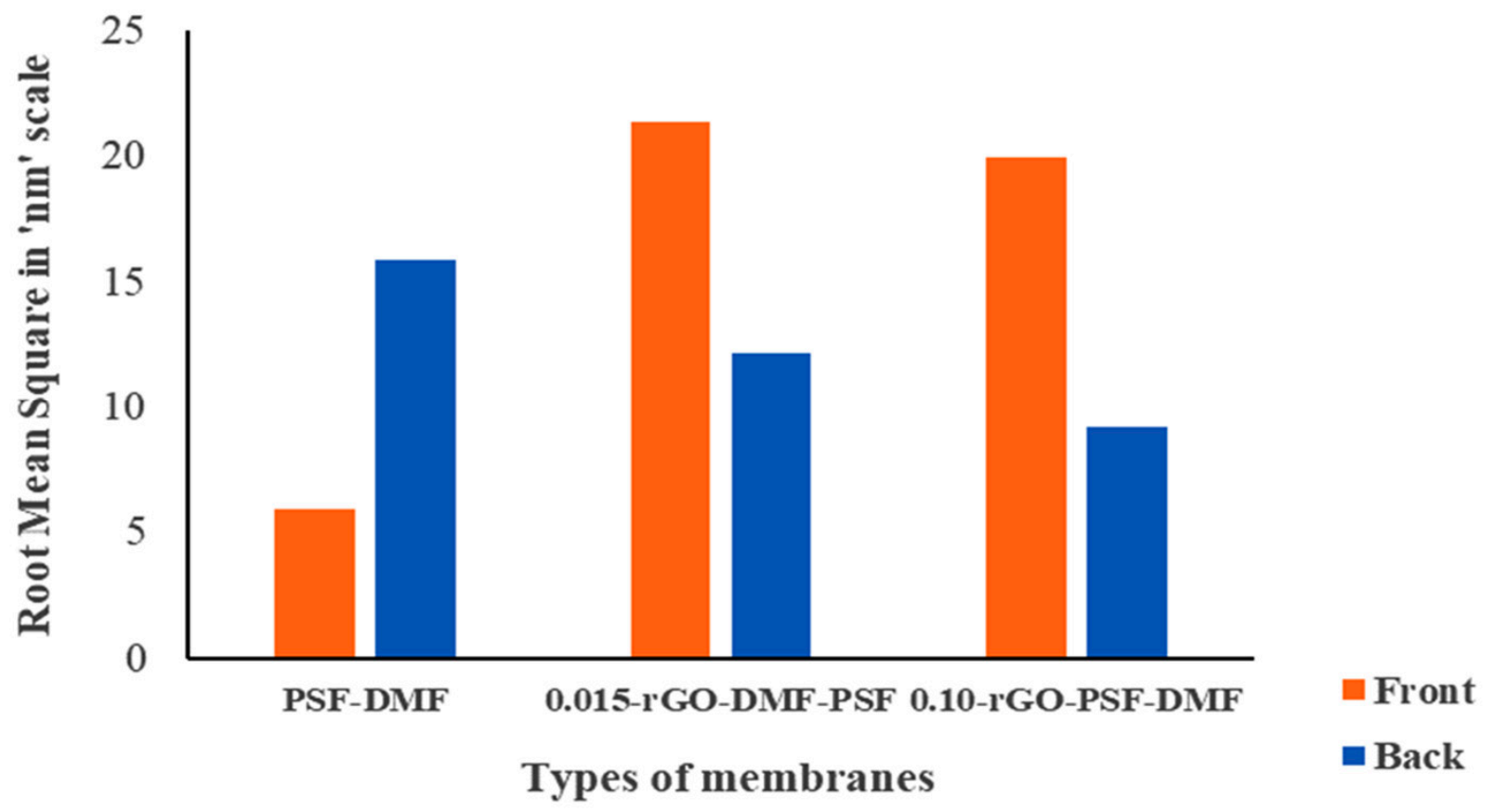

(a)

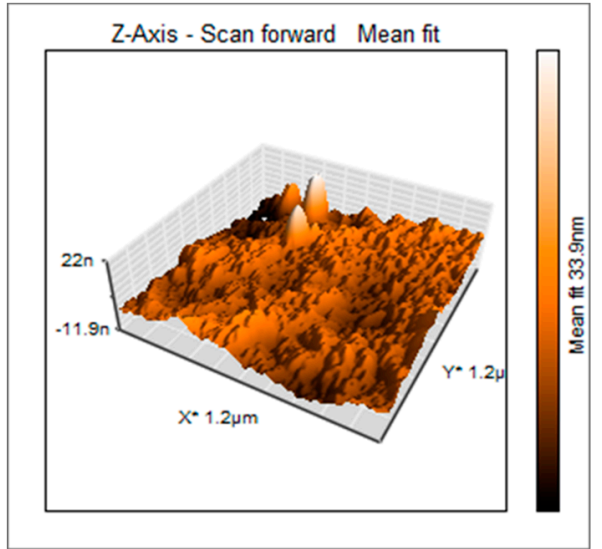

Sample A

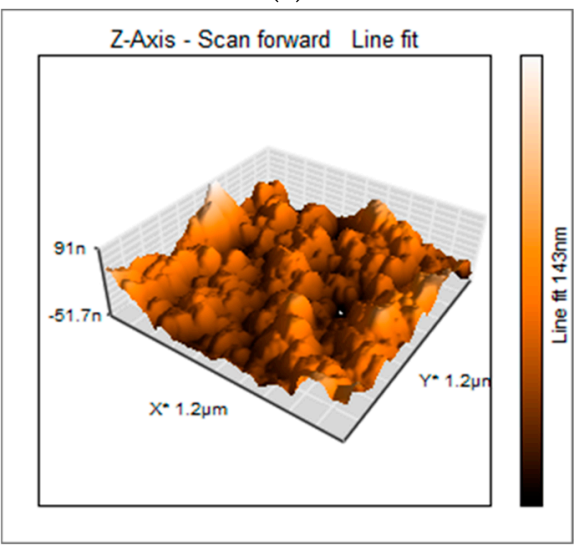

Sample B

(b)

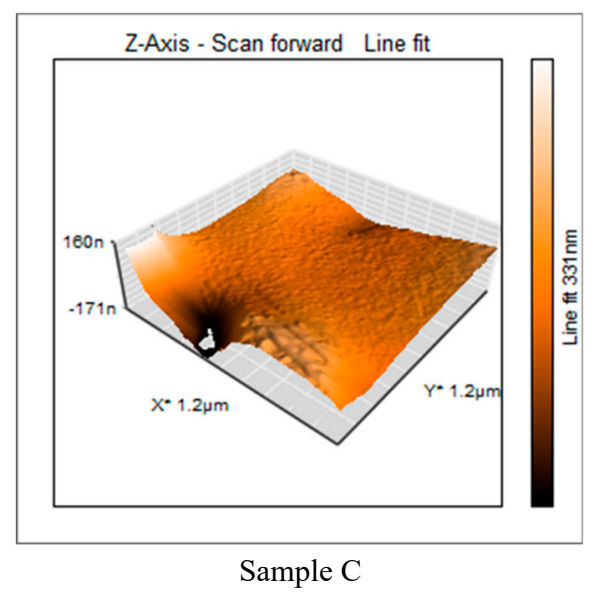

Sample C

Figure 7. (a) Root mean square roughness from atomic force microscopy (AFM) for sample A, B, and C membranes. (b) AFM image analysis of different membranes. 


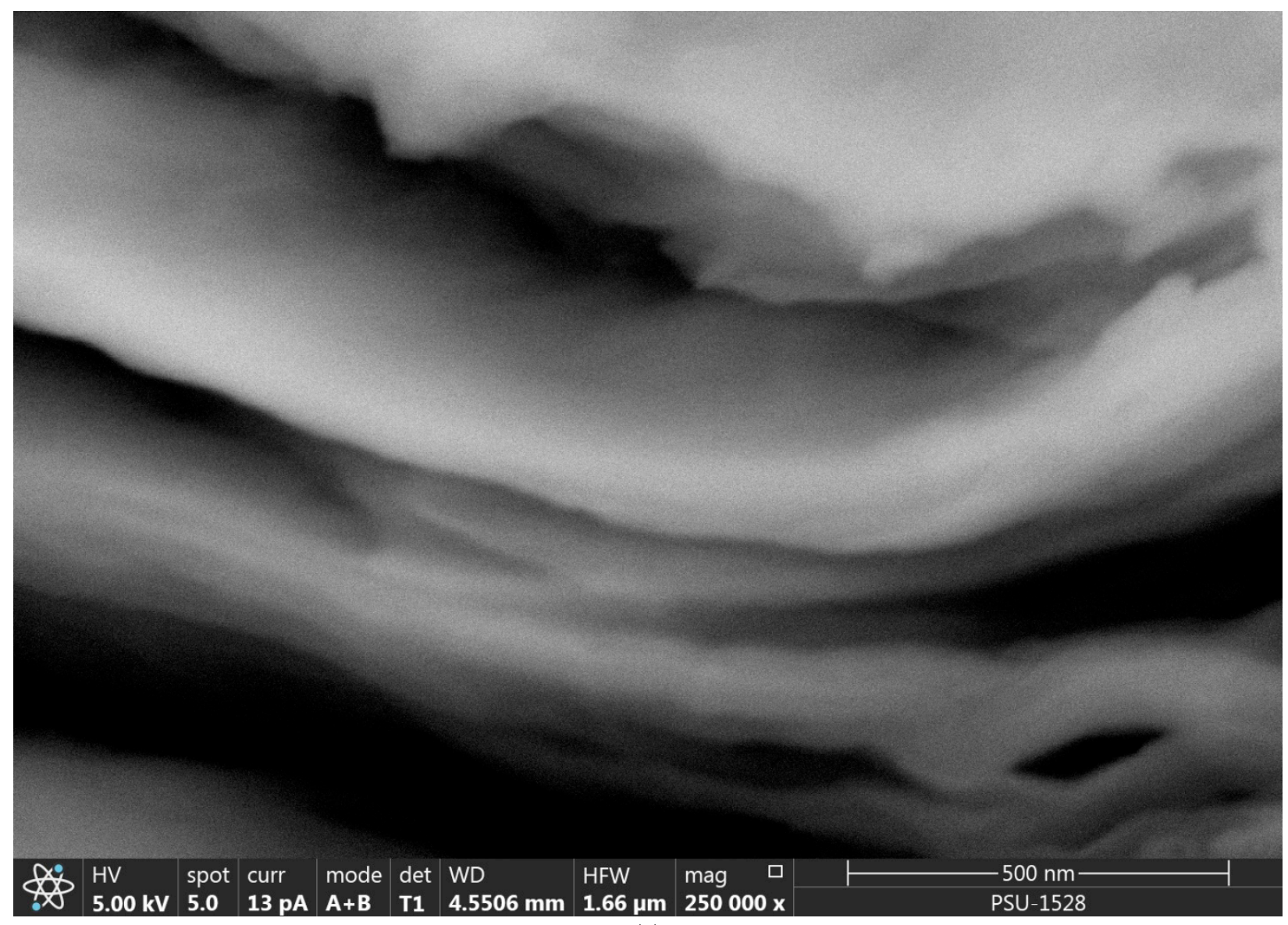

(a)

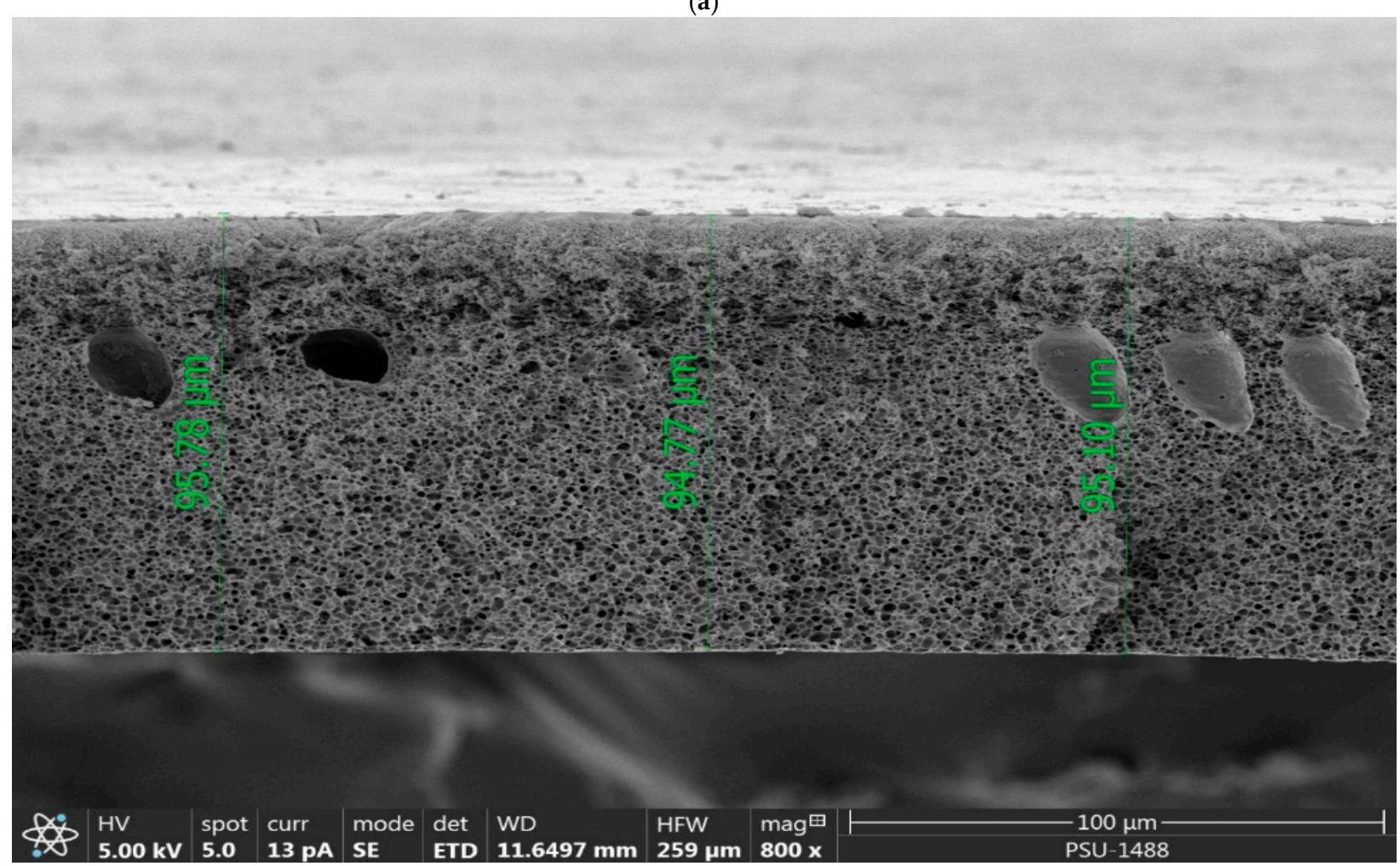

(b)

Figure 8. Cont. 


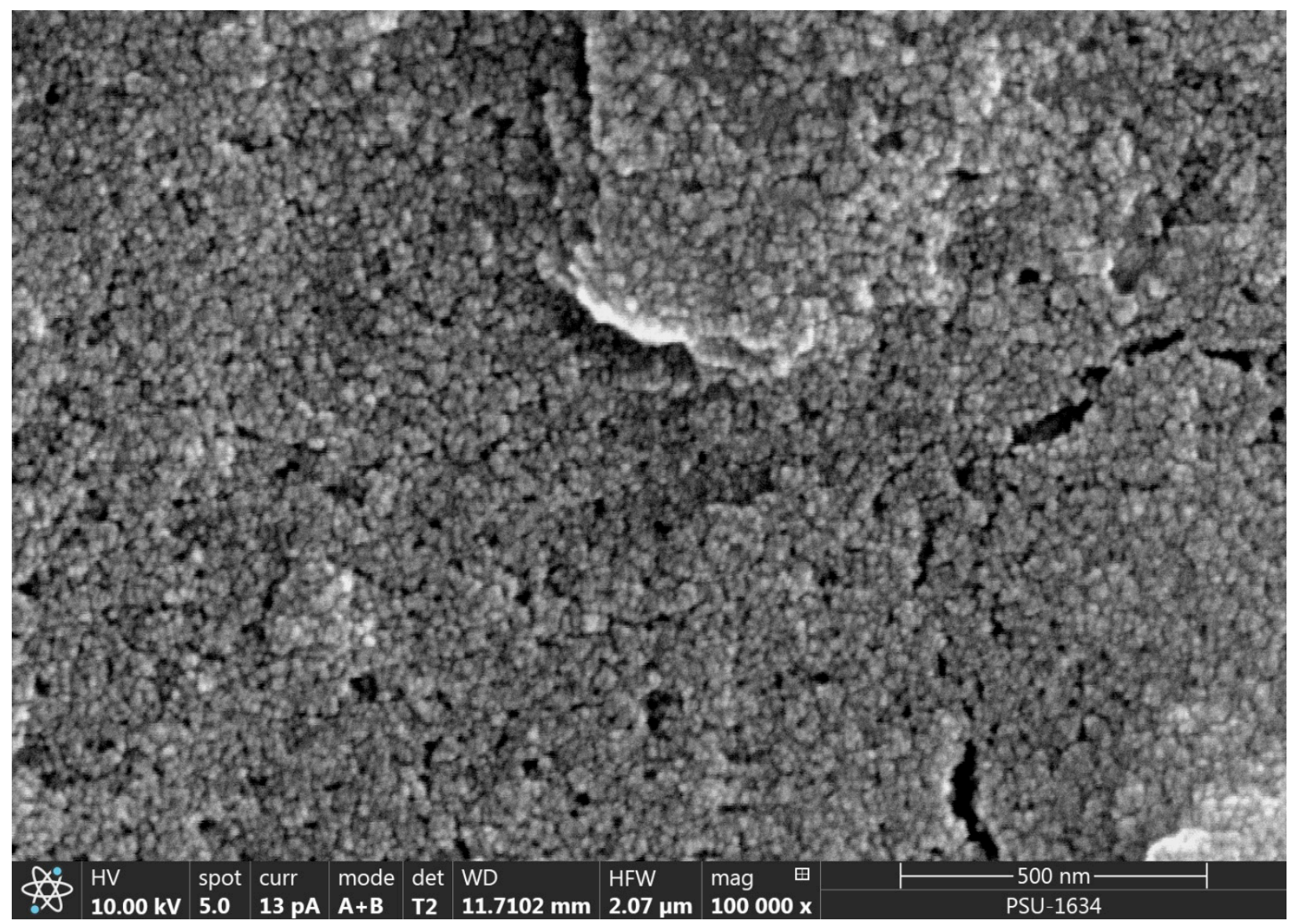

(c)

Figure 8. (a) FE-SEM image of reduced graphene oxide nanomaterials. (b) FE-SEM image for an average-thickness membrane. (c) FE-SEM image of iron particles on the surface of the sample C membrane.

FE-SEM image analysis after iron filtration for different membranes showed that sample A and sample B membranes had a low content of iron particles on the surface.

In Figure $8 \mathrm{c}$, the sample $\mathrm{C}$ membrane shows a high content of iron particles on the surface and the top layer of the cross-section view [16].

\subsection{TEM Image and Selected Area Electron Diffraction (SAED) Analysis}

The TEM image shows a reduced graphene oxide formation. Lattice spacing was $4.13 \mathrm{~nm}$ for 10 lattice spaces. Each lattice space was calculated at $0.413 \mathrm{~nm}$ (Figure 9a). SAED pattern image analysis was performed using the formula,

$$
(d)=\frac{1}{R}
$$

where $d$ is the lattice space and $R$ is the radius between the first opposite two spots confirming the lattice space (Figure 9c) [17]. 


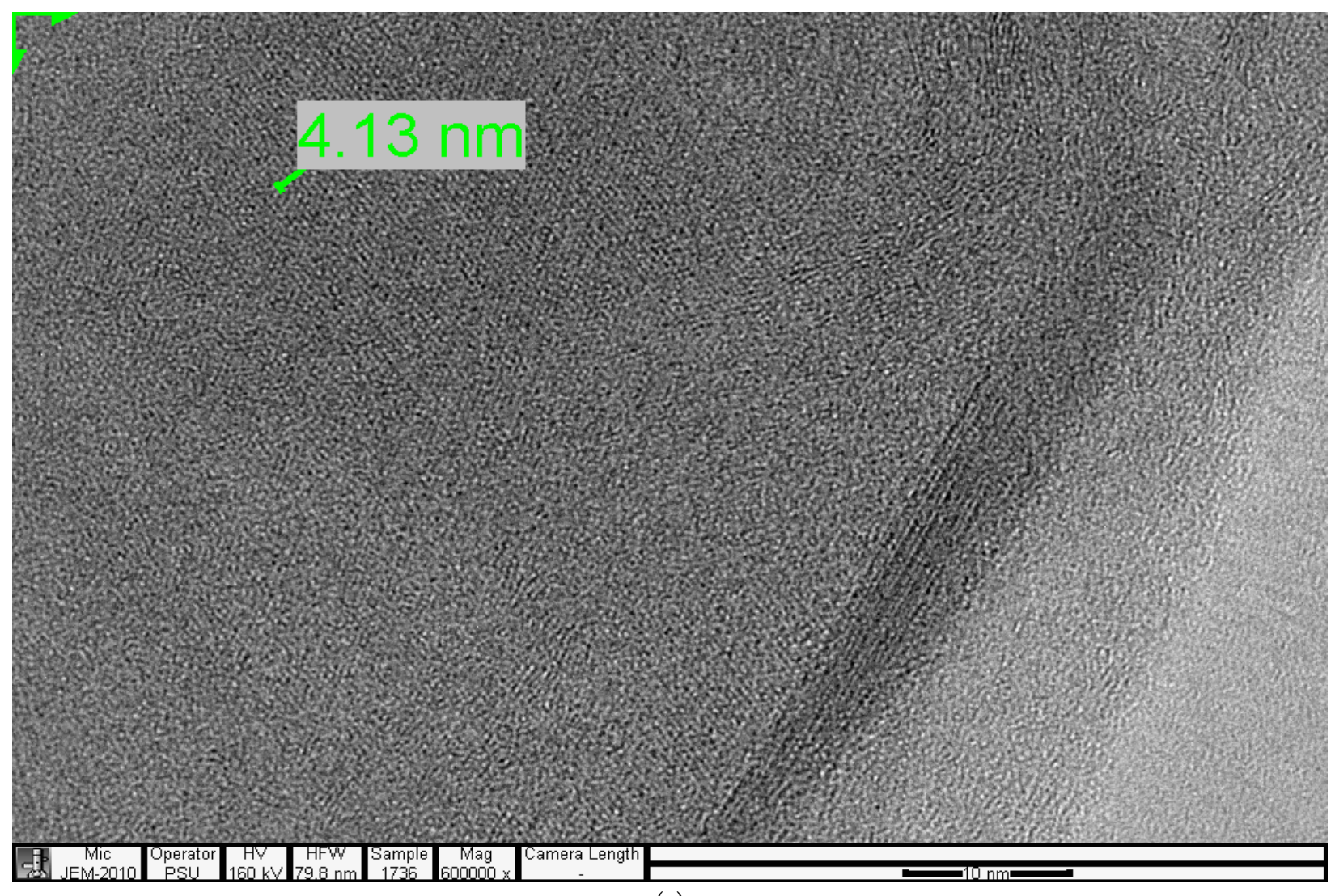

(a)

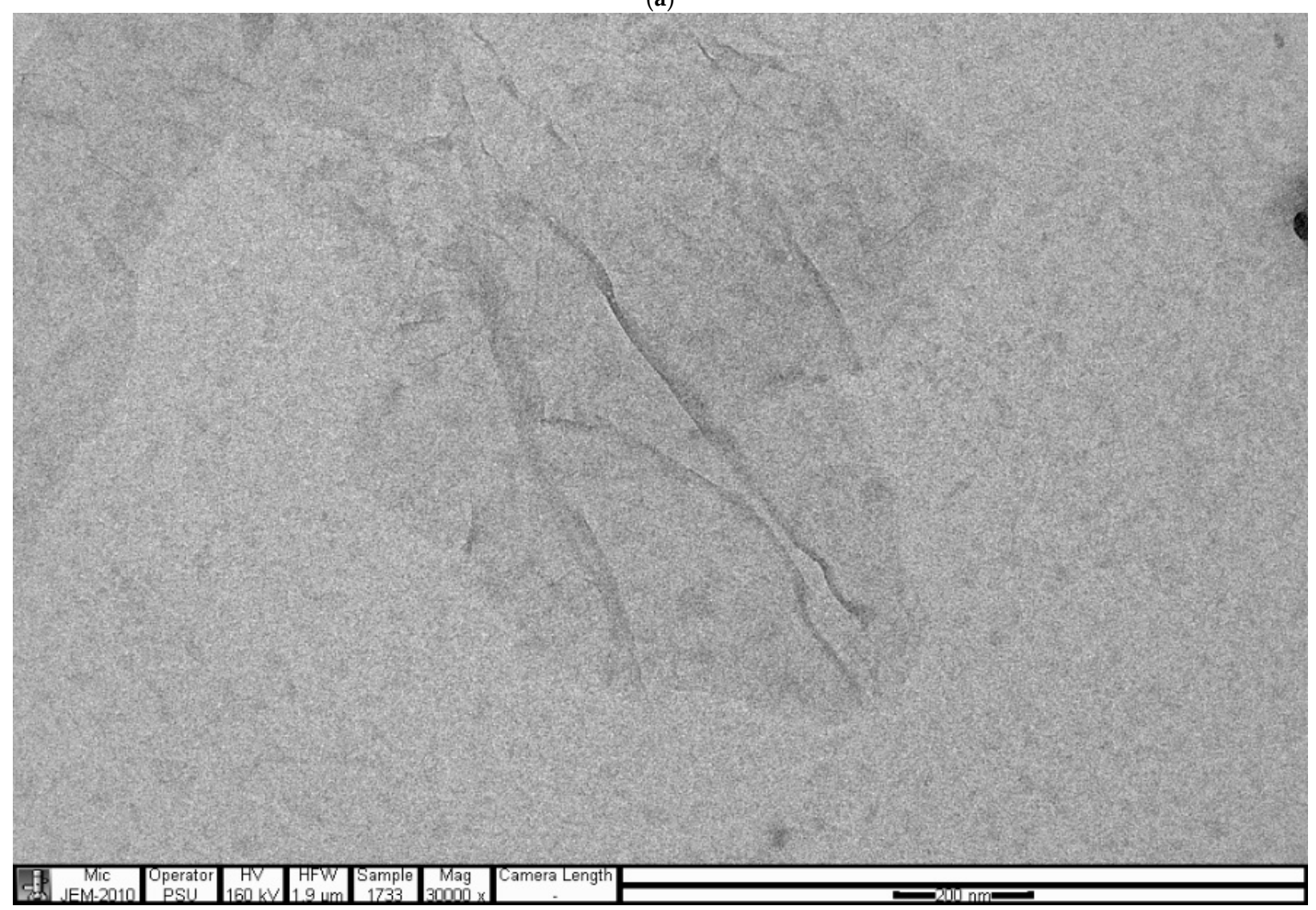

(b)

Figure 9. Cont. 


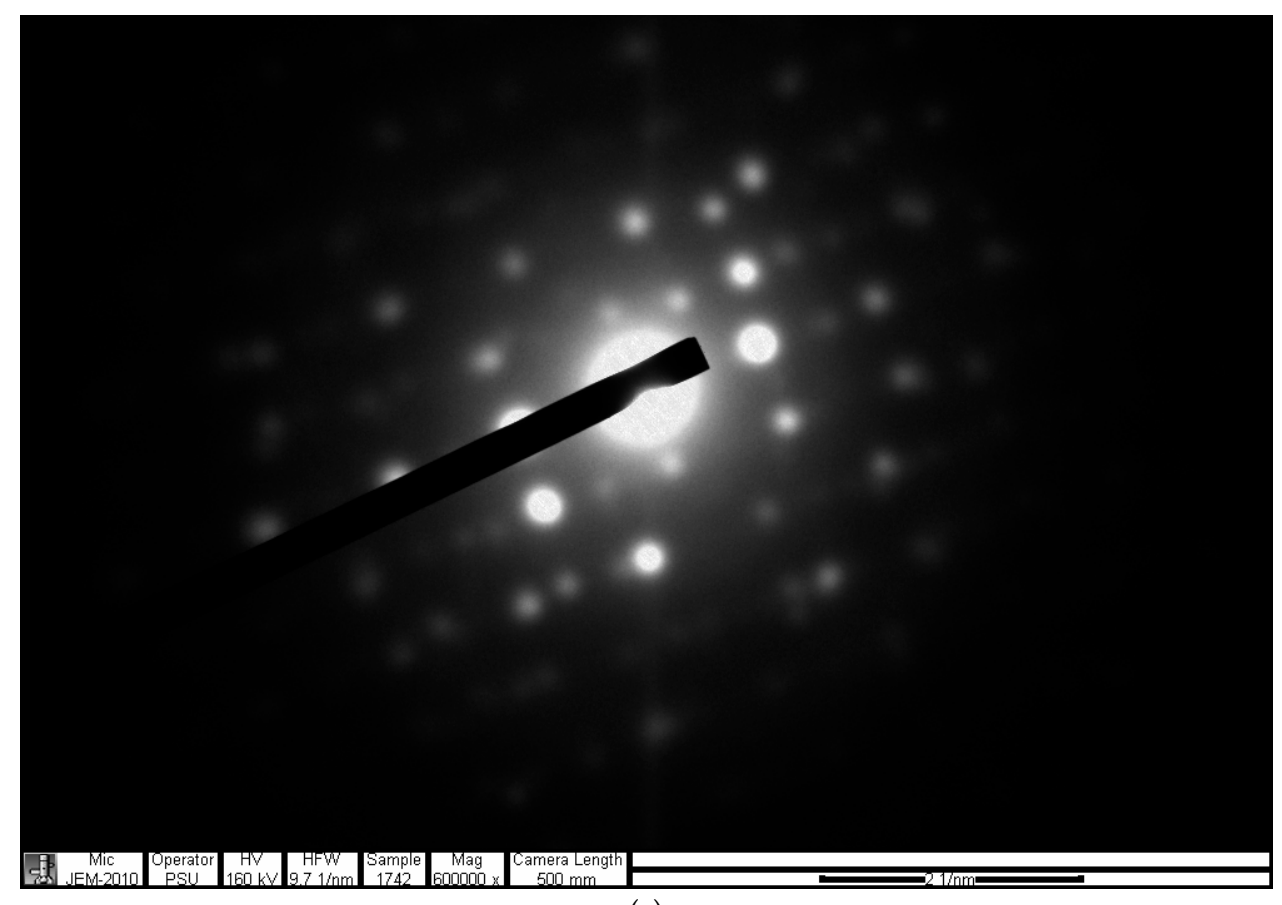

(c)

Figure 9. (a) TEM image for lattice space analysis. (b) TEM image of reduced graphene oxide nanomaterials. (c) Selected Area Electron Diffraction (SAED) pattern.

\subsection{Energy Dispersive X-ray (EDX) Analysis}

EDX analysis showed a $62.7 \mathrm{wt} \%$ of carbon (C) and $30.1 \mathrm{wt} \%$ of oxygen $(\mathrm{O})$ in the reduced graphene oxide nanomaterial (Figure 10a).

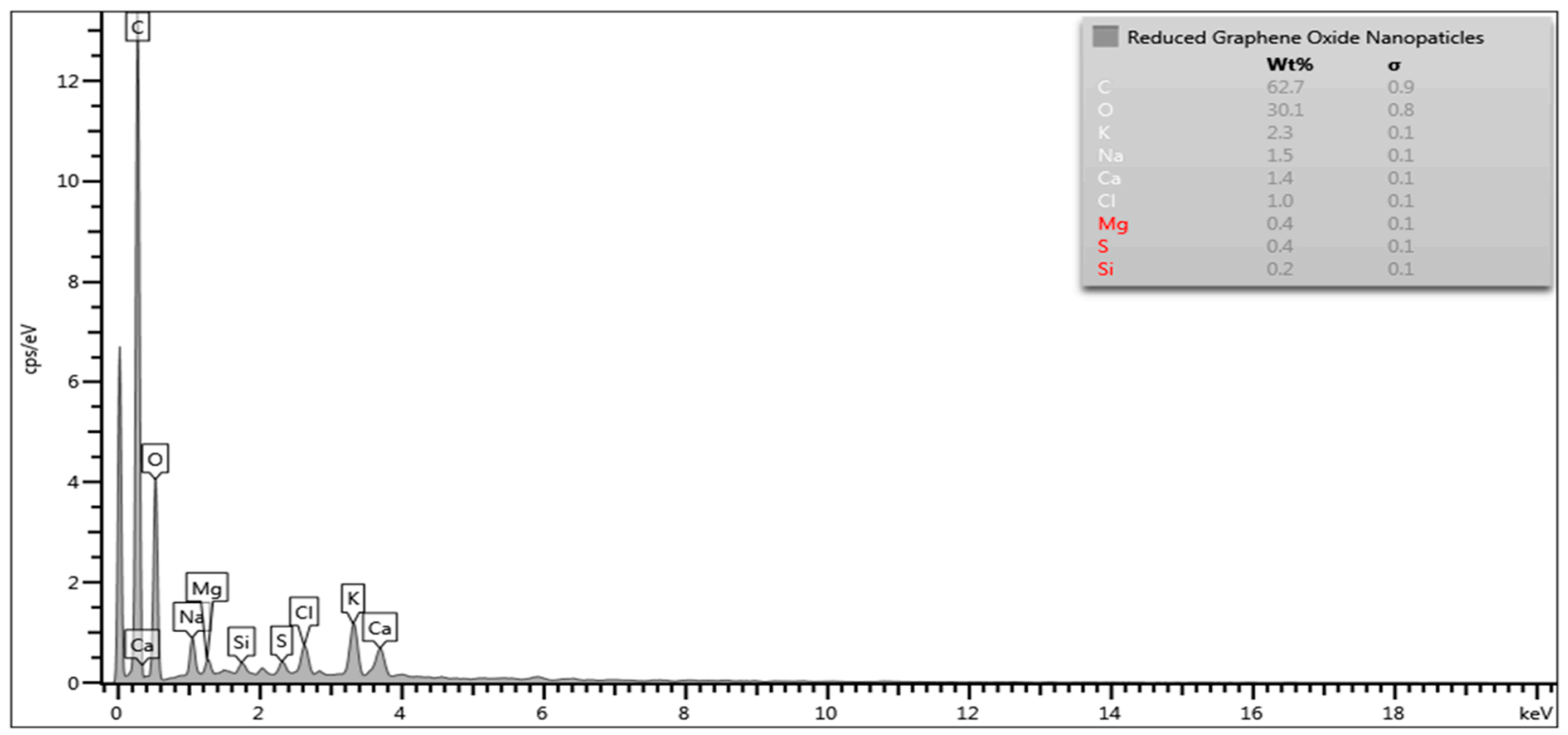

(a)

Figure 10. Cont. 


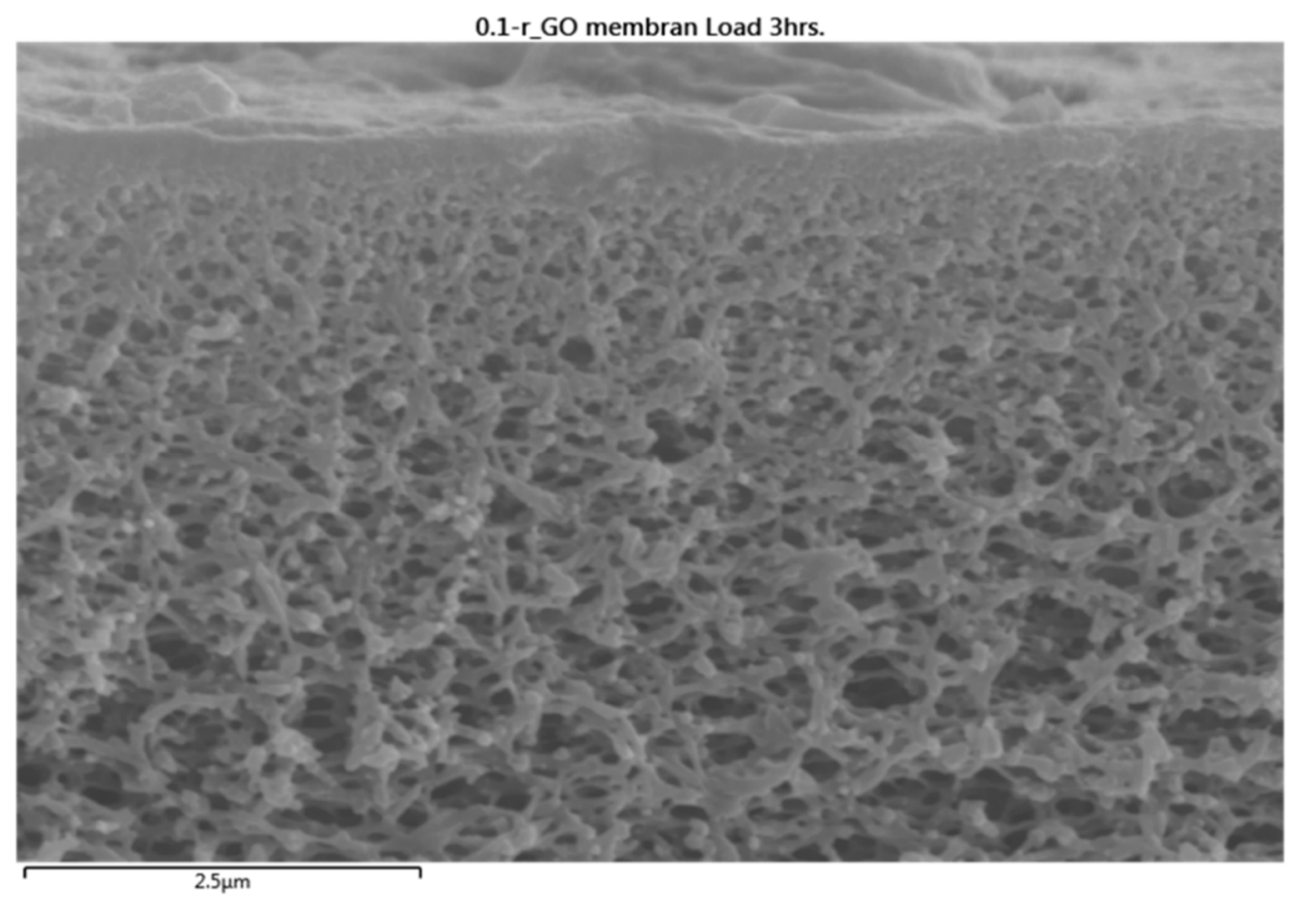

(b)

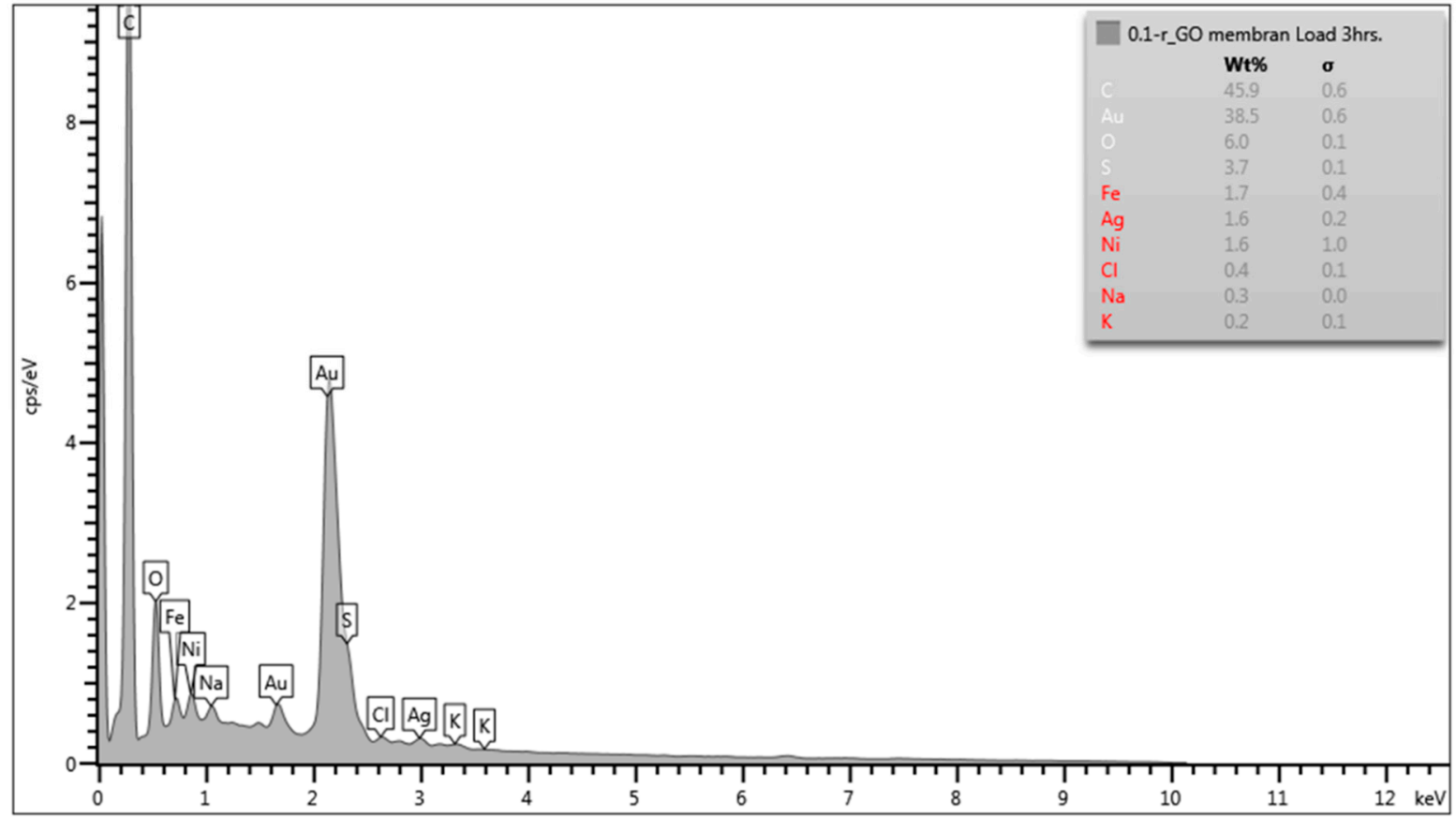

(c)

Figure 10. (a) Energy dispersive X-ray (EDX) analysis of reduced graphene oxide nanomaterial. (b) EDX analysis of the cross-section view of the sample $\mathrm{C}$ membrane after iron water filtration. (c) EDX analysis of the sample C membrane.

EDX analysis of the sample B membrane before iron water filtration showed an absence of iron particles.

After iron water filtration, EDX analysis showed a $0.2 \mathrm{wt} \%$ iron content in the sample B membrane. Similarly, the sample C membrane showed a $1.7 \mathrm{wt} \%$ iron content (Figure 10c) [18]. 


\subsection{Fourier Transform Infrared Spectroscopy (FTIR) Analysis}

FTIR analysis showed the change in bond angle and bond length, and confirmed the functional groups that are attached to the r-GO nanomaterial and sample $\mathrm{C}$ membrane (Figure 11).

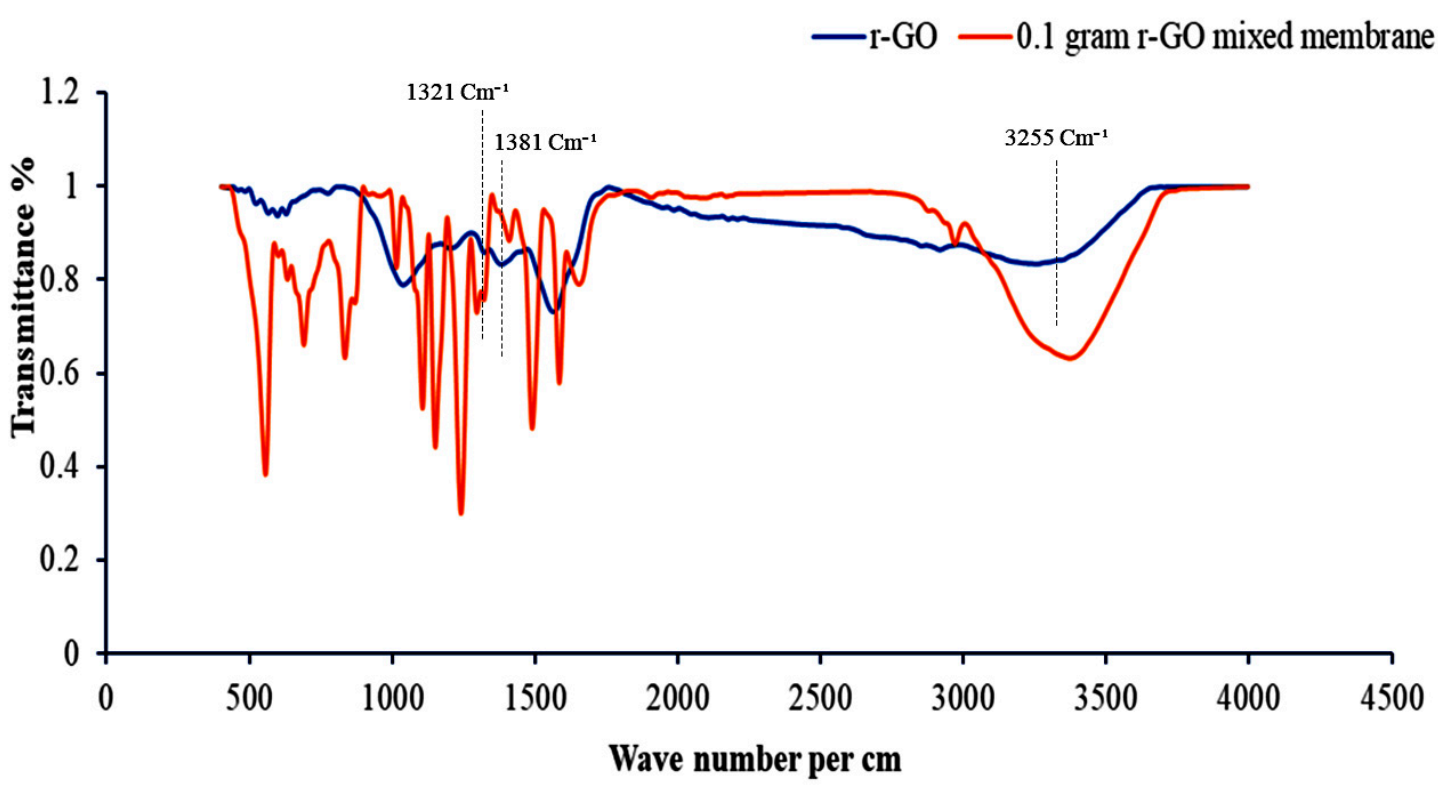

Figure 11. FTIR analysis of r-GO nanomaterials and sample $C$ membrane before filtration.

Wave numbers 1321 and $1381 \mathrm{~cm}^{-1}$ confirmed the presence of phenolic compounds and wave number $3255 \mathrm{~cm}^{-1}$ confirmed the presence of carboxylic acid on the surface of the r-GO nanomaterial. The functional groups attached to the sample $\mathrm{C}$ membrane were found to be similar to those attached to reduced graphene oxide nanomaterial, confirming the presence of reduced graphene oxide nanomaterials in the membrane [19].

\subsection{Water Permeability (Pure Water Flux)}

Water permeation was tested using prepared membranes at different pressures $(1,2,3$, 4 , and 5 bar) that were held constant for five minutes.

Water permeation or pure water flux was calculated from the formula,

$$
\operatorname{Flux}(J)=\frac{V}{A t}
$$

where $J$ is water flux, $V$ is the volume of water in liters, $A$ is the area of membrane in meters square, and $t$ is time in hours.

The water permeation $(\mathrm{L})$ of the different membranes was calculated using the following formula,

$$
\mathrm{L}_{\mathrm{P}}=\text { Slope }(\mathrm{m}) \times 2.77 \times 10^{-10} \mathrm{M} \mathrm{S}^{-1} \mathrm{~Pa}^{-1}
$$

where $\mathrm{m}$ is the slope of the line from the graph of water flux versus pressure (Figure 12, Table 2) [20].

Table 2. Normal deionized water permeability.

\begin{tabular}{ccc}
\hline Membranes & Slope $(\mathrm{m})$ & Permeation $\left(\mathbf{M ~ S}^{-\mathbf{1}} \mathbf{P a}^{-\mathbf{1}} \mathbf{)}\right.$ \\
\hline Sample A & 0.0171 & $4.7367 \times 10^{-12}$ \\
Sample B & 0.017 & $4.709 \times 10^{-12}$ \\
Sample C & 0.0571 & $1.58167 \times 10^{-11}$ \\
\hline
\end{tabular}



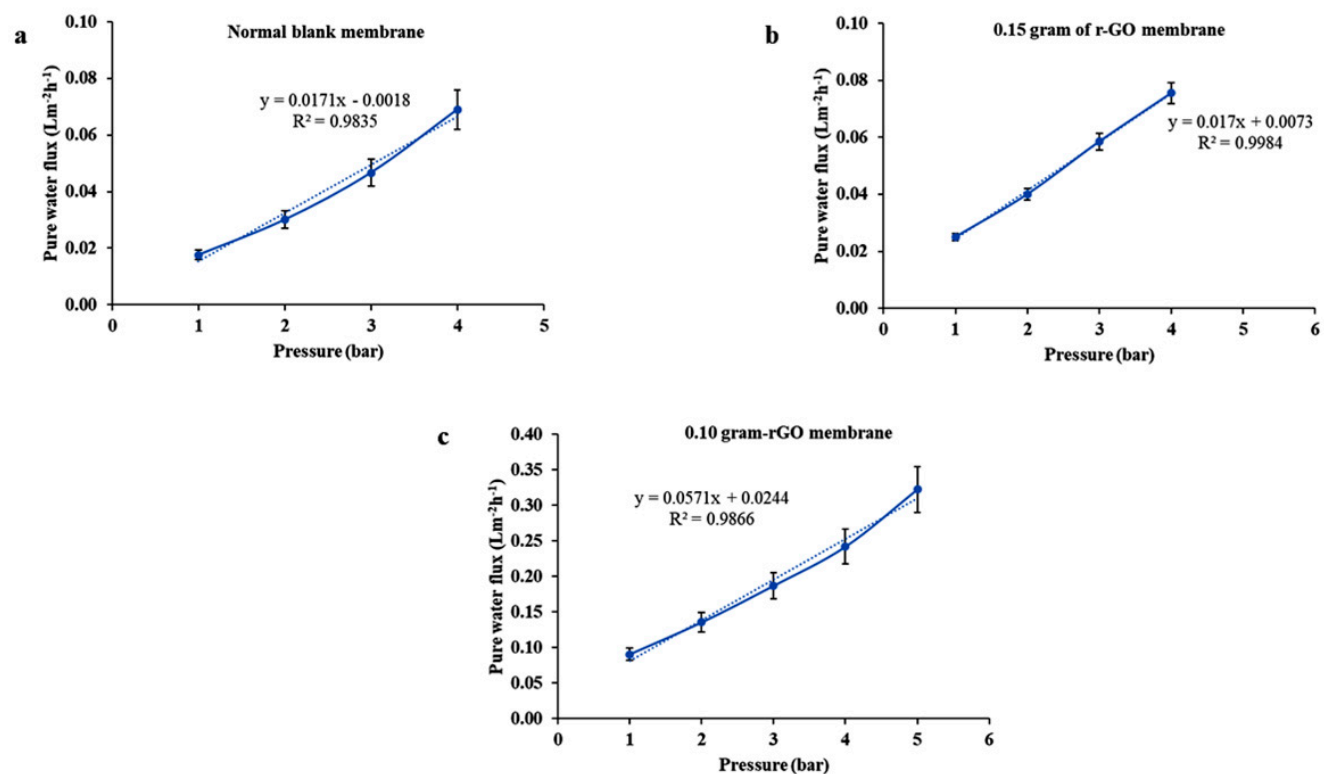

Figure 12. Normal deionized water permeability (a) Sample A (b) Sample B (c) Sample C.

\subsection{Rejection}

The percentage of iron rejection $(R)$ for different membranes was calculated from the formula,

$$
R=\left(1-\frac{C^{1}}{C^{2}}\right) 100 \%
$$

where $C^{1}$ is concentration after permeation and $C^{2}$ is concentration before permeation.

For this, $0.025 \mathrm{~g}$ of iron nitrate was mixed with $2000 \mathrm{~mL}$ of de-ionized water and stirred for $20 \mathrm{~min}$. Iron rejection was performed for $240 \mathrm{~min}$ at a constant 5 bar pressure. At each $10 \mathrm{~min}$ interval, filtered water was weighed to calculate water flux and observe fouling.

ICP testing identified the presence of iron before rejection as $1.799 \mathrm{mg} / \mathrm{L}$. After rejection, the sample A membrane had an iron presence $0.100 \mathrm{mg} / \mathrm{L}$. Similarly, iron rejection using sample B membrane produced an iron presence of $0.110 \mathrm{mg} / \mathrm{L}$ and sample $\mathrm{C}$, $0.076 \mathrm{mg} / \mathrm{L}$.

The percentage of rejection by the sample A, B, and C membranes was $94.44 \%, 93.88 \%$, and $95.77 \%$, respectively (Figure 13) [21].

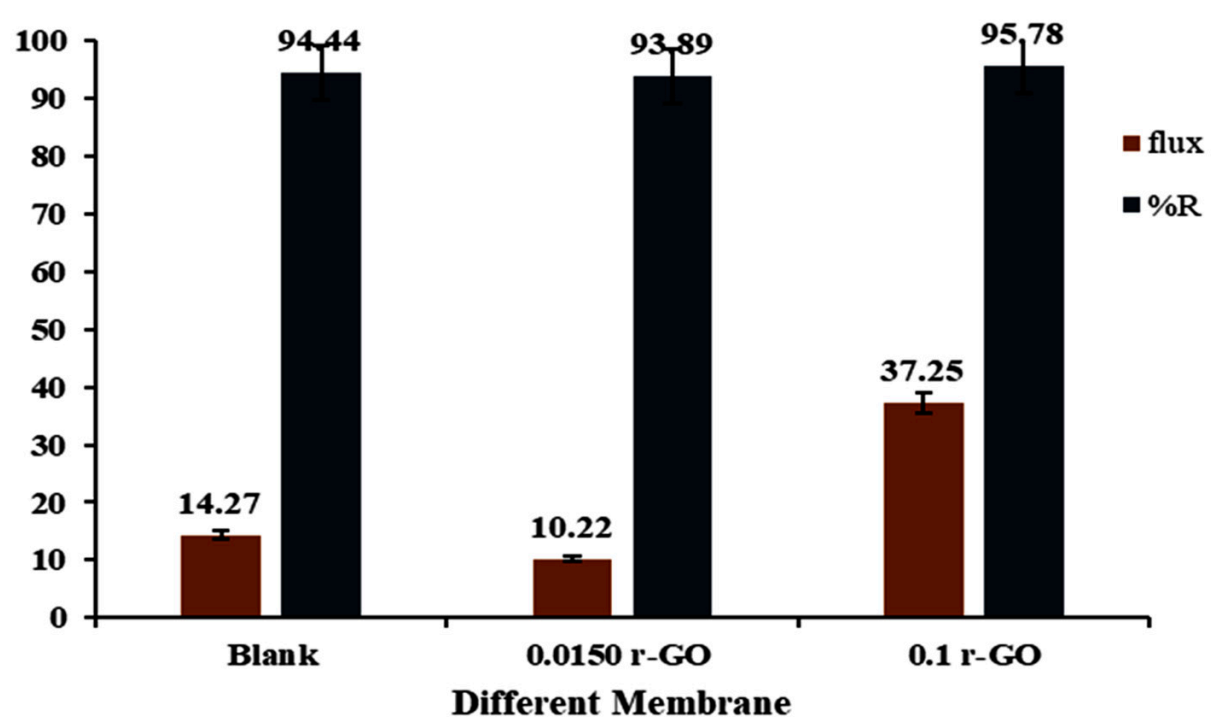

Figure 13. Water flux and rejection of iron after filtration using different contents of reduced graphene oxide nanomaterials in the membrane filter. 


\section{Discussion}

The mass production of reduced graphene oxide sheets using physical methods, such as pulse laser ablation (PLA) or physical vapor deposition (PVD), at a low cost is extremely challenging. Chemical methods, such as chemical vapor deposition (CVD), are hazardous to the environment and human health. Nowadays, reduced graphene oxide nanomaterials are of interest to researchers in water filtration applications due to their nanosized pores; however, a cost-effective and eco-friendly synthesis method is still required.

In this water filtration study, reduced graphene oxide nanomaterials were biologically synthesized using Callistemon viminalis leaf extract. Here, the phenolic compounds and carboxylic acid present in leaf extract act as single-sheet separation and capping agents in the graphene oxide. Reduced graphene oxide nanomaterials are more hydrophilic in nature and can be used for iron metal removal from drinking water. Higher iron rejection and water flux were obtained with higher amounts of reduced graphene oxide in the membrane, which predicts that a higher volume of water can be obtained at the time of nanofiltration. At the nanoscale level, nanofiltration guarantees iron removal due to nanoscale pores present in membrane, but more research is needed to cost-effectively commercialize this process. To understand the stability of membrane after several times of use, further research is required, but all commercially available membranes have drawbacks after reuse. Our findings show that mass production of reduced graphene oxide nanomaterials could be possible in the near future for eco-friendly heavy metals removal from drinking water at a low cost, thereby overcoming the challenges posed by physical and chemical methods in mass production for reduced graphene oxide nanomaterials.

\section{Conclusions}

In this research, the biosynthesis of reduced graphene oxide nanomaterials from Callistemon viminalis leaf extract was discussed. Reduced graphene oxide nanomaterials were analyzed using FE-SEM-EDX, X-RD, FTIR, TEM, and SAED diffraction patterns, confirming its biological synthesis. FTIR confirmed the presence of phenolic compounds at 1321 and $1381 \mathrm{~cm}^{-1}$ wave numbers and the presence of carboxylic acid at $3255 \mathrm{~cm}^{-1}$. Reduced graphene oxide membrane filters were prepared by varying the content of reduced graphene oxide nanomaterials in PSF-DMF membranes. The contact angle with a high content of reduced graphene oxide nanomaterials (i.e., sample C) was $74.2^{\circ}$, whereas that for the PSF-DMF membrane (i.e., sample A) and the one with a low content of reduced graphene oxide nanomaterials (i.e., sample B) were $79.4^{\circ}$ and $79.6^{\circ}$, respectively, demonstrating the hydrophilicity of increasing the reduced graphene oxide nanomaterials content in the membrane. Atomic force microscopy showed far less surface roughness on the front side for the PSF-DMF (i.e., sample A) membrane than with a higher content of reduced graphene oxide (i.e., sample $\mathrm{C}$ ) and lower content of reduced graphene oxide (i.e., sample B). However, surface roughness on the back side of the sample A membrane was higher than that of samples B and C. EDX analysis showed a $0.2 \mathrm{wt} \%$ of iron in the sample with a lower content of reduced graphene oxide nanomaterials after iron rejection compared with a $1.7 \mathrm{wt} \%$ of iron in the sample with a higher content reduced graphene oxide nanomaterials after iron rejection. Iron rejection of the sample with a higher content of reduced graphene oxide nanomaterials was highest at $95.77 \%$.

Author Contributions: All the authors contributed to the preparation of this manuscript. P.K.J. performed all the laboratory experiments and prepared the draft manuscript. W.K. designed the framework for the experiments. C.C. analyzed the experimental data. M.S.C. helped with the manuscript preparation. K.T. conceptualized the research and corrected the manuscript. All authors have read and agreed to the published version of the manuscript.

Funding: This research was funded by TGIST, the National Science and Technology Developmental Agency, Pathum Thani 12120, Thailand, Agreement No. SCA-CO-2562-9699-EN.

Institutional Review Board Statement: Not applicable. 
Informed Consent Statement: Not applicable.

Data Availability Statement: Not applicable.

Acknowledgments: This research was supported by Prince of Songkla University from grant number ENV6402012N.

Conflicts of Interest: The authors declare no conflict of interest.

\section{References}

1. WHO. Water-Related Diseases; WHO, World Health Organization: Geneva, Switzerland, 2014; Available online: http://www.who. int/water_sanitation_health/diseases-risks/diseases/diarrhoea/en/ (accessed on 6 July 2020).

2. Tchounwou, P.B.; Yedjou, C.G.; Patlolla, A.K.; Sutton, D.J. Heavy metal toxicity and the environment. Exp. Suppl. 2012, 101, 133-164.

3. Singh, R.; Gautam, N.; Mishra, A.; Gupta, R. Heavy metals and living systems: An overview. Indian J. Pharmacol. 2011, 43, 246-253. [CrossRef] [PubMed]

4. Iron in Drinking-Water. Geneva, Switzerland. 2003. Available online: https://www.who.int/water_sanitation_health/waterquality / guidelines/chemicals/iron.pdf?ua=1 (accessed on 5 September 2020).

5. Bolisetty, S.; Peydayesh, M.; Mezzenga, R. Sustainable technologies for water purification from heavy metals: Review and analysis. Chem. Soc. Rev. 2019, 21, 48. [CrossRef] [PubMed]

6. Tanne, N.; Xu, R.; Zhou, M.; Zhang, P.; Wang, X.; Wen, X. Influence of pore size and membrane surface properties on arsenic removal by nanofiltration membranes. Front. Environ. Sci. Eng. 2019, 13, 19. [CrossRef]

7. Liu, Y. Application of graphene oxide in water treatment. IOP Conf. Ser. Earth. Environ. Sci. 2017, 94, 012060. [CrossRef]

8. Jayakaran, P.; Nirmala, G.S.; Govindarajan, L. Qualitative and Quantitative Analysis of Graphene-Based Adsorbents in Wastewater Treatment. Int. J. Chem. Eng. 2019. [CrossRef]

9. Lee, G.; Kim, B.S. Biological reduction of graphene oxide using plant leaf extracts. Biotechnol. Prog. 2014, 30, 463-469. [CrossRef] [PubMed]

10. Nguyen, H.T.V.; Ngo, T.H.A.; Do, K.D.D.; Nguyen, M.N.; Dang, N.T.T.; Nguyen, T.T.H.; Vien, V.; Vu, T.A. Preparation and Characterization of a Hydrophilic Polysulfone Membrane Using Graphene Oxide. J. Chem. 2019, 2019, 3164373. [CrossRef]

11. Kanthal, L.K.; Dey, A.; Satyavathi, K.; Bhojaraju, P. GC-MS analysis of bio-active compounds in methanolic extract of Lactuca runcinata DC. Pharmacogn. Res. 2014, 6, 58-61. [CrossRef] [PubMed]

12. Aragaw, B.A. Reduced graphene oxide-intercalated graphene oxide nano-hybrid for enhanced photoelectrochemical water reduction. J. Nanostruct. Chem. 2020, 10, 9-18. [CrossRef]

13. Hsueh, Y.-H.; Hsieh, C.-T.; Chiu, S.-T.; Tsai, P.-H.; Liu, C.-Y.; Ke, W.-J. Antibacterial Property of Composites of Reduced Graphene Oxide with Nano-Silver and Zinc Oxide Nanoparticles Synthesized Using a Microwave-Assisted Approach. Int. J. Mol. Sci. 2019, 20, 5394. [CrossRef] [PubMed]

14. Kertész, S.; De Freitas, T.B.; Hodúr, C. Characterization of polymer membranes by contact angle goniometer. Analecta Tech. Szeged. 2014, 18, 18-22. [CrossRef]

15. Carvalho, A.L.; Maugeri, F.; Silva, V.; Hernández, A.; Palacio, L.; Pradanos, P. AFM analysis of the surface of nanoporous membranes: Application to the nanofiltration of potassium clavulanate. J. Mater. Sci. 2011, 46, 3356-3369. [CrossRef]

16. Rezaee, R.; Nasseri, S.; Mahvi, A.H.; Nabizadeh, R.; Mousavi, S.A.; Rashidi, A.; Jafari, A.; Nazmara, S. Fabrication and characterization of a polysulfone-graphene oxide nanocomposite membrane for arsenate rejection from water. J. Environ. Health Sci. Eng. 2015, 13, 61. [CrossRef] [PubMed]

17. Aliyev, E.; Filiz, V.; Khan, M.M.; Lee, Y.J.; Abetz, C.; Abetz, V. Structural Characterization of Graphene Oxide: Surface Functional Groups and Fractionated Oxidative Debris. Nanomaterials 2019, 9, 1180. [CrossRef] [PubMed]

18. Elcik, H.; Cakmakci, M.; Ozkaya, B. Preparation and characterisation of novel polysulfone membranes modified with Pluronic F-127 for reducing microalgal fouling. Chem. Pap. 2017, 71, 1271-1290. [CrossRef]

19. Faniyi, I.O.; Fasakin, O.; Olofinjana, B.; Adekunle, A.S.; Oluwasusi, T.V.; Eleruja, M.A.; Ajayi, E.O.B. The comparative analyses of reduced graphene oxide (RGO) prepared via green, mild and chemical approaches. SN Appl. Sci. 2019, 1, 1181. [CrossRef]

20. Shukla, A.K.; Alam, J.; Alhoshan, M.; Dass, L.A.; Ali, F.A.A.; R, M.M.; Mishra, U.; Ansari, M.A. Removal of heavy metal ions using a carboxylated graphene oxide-incorporated polyphenylsulfone nanofiltration membrane. Environ. Sci. Water Res. Technol. 2018, 4, 438-448. [CrossRef]

21. Zhao, G.; Hu, R.; Li, J.; Zhu, H. Graphene oxide quantum dots embedded polysulfone membranes with enhanced hydrophilicity, permeability and antifouling performance. Sci. China Mater. 2019, 62, 1177-1187. [CrossRef] 